\title{
Editorial: The Biological Significance of Fever
}

\author{
Istvan Berczi and Toshihiko Katafuchi
}

In the ancient cultures of Persia, Greece and in the Roman Empire fever was believed to posses healing powers [1]. This sentiment was maintained until modern times, when Boivin [2] isolated the first pyrogen, lipopolisaccharide (LPS), or endotoxin, from Gramnegative bacteria. LPS is an outstanding pyrogen. Countless studies with LPS indicated that it is capable of inducing a disease known as "endotoxin shock", which may have lethal consequences [3]. Later it was discovered that sub-toxic dose of endotoxin actually provided protection to animals against infectious disease and to other harmful insults. This condition was known as "endotooxin tolerance". LPS, especially in the detoxified form, could be used as immunological adjuvant and was effective for the treatment of radiation disease, drug induced immunosuppression, bone marrow failure, and had a beneficial effect on a number of other pathological conditions [4].

Studies of LPS toxicity in various species revealed that domesticated mammals have extreme sensitivity to LPS, laboratory rodents showed more resistance, and chickens, frogs and fish were resistant. It seems apparent that LPS toxicity is proportional to the development of the immune system of the animals exposed [5]. Subsequent experiments indicated that it is not LPS but the cytokines that LPS releases from the innate immune system (INIM), which kills the host [6, 7].

These observations led to the conclusion that LPS is an evolutionally preserved cross-reactive homologous epitopes (homotopes), which are recognized by INIM antigen receptors. These receptors evolved to recognize highly preserved epitopes as the receptors are coded by germ line gene products, which are constant [8].
The disease caused by LPS is acute febrile illness, or the acute phase response (APR) as it is called by modern terminology. Fever is an absolute hallmark of this condition. This fever is caused by activation of the innate immune system which release endogenous pyrogens (cytokines) [9].

Pathogenic, neurogenic, and psychogenic fevers may be distinguished. Pathogenic fever is the hallmark of infectious disease. An invading microorganism releases endotoxin that stimulates macrophages to synthesize a variety of pyrogenic compounds called cytokines. Carried in blood, these cytokines reach the perivascular spaces of the organum vasculosum laminae terminalis (OVLT) and other regions near the brain where they promote the synthesis and release of prostaglandin (PGE2). This prostaglandin then penetrates the blood-brain barrier to evoke the autonomic and behavioral responses characteristic of fever. But then once expressed, fever does not continue unchecked; endogenous antipyretics act on the septum to limit the rise in body temperature [10].

Why is fever needed for APR? Some data in the literature indicate that higher temperature is an immunostimulant $[11,12]$. One may propose that, biological reactions speed up on higher temperatures and metabolism is elevated. Patients with febrile illness loose weight rapidly because of the fast metabolic breakdown of their own tissues. Fever should contribute to the establishment of catabolic conditions during APR. Catabolism of host tissues is the only way to fuel the intense emergency defense reaction in APR.

Today it is known that the CNS is immunocompetent organ, it is capable of recognizing infectious agents by toll-like receptors (TLR). Moreover, the CNS has 
a critical role in the regulation of immune reactions, of acute illness, inflammation (neurogenic inflammation). Immune reactions may undergo pavlovian conditioning, where immune reactions are mounted in the absence of the antigen. This was interpreted that the CNS is capable of responding to anticipated danger [13].

Oka and Oka in this issue describe psychogenic fever [14]. Apparently this condition is presented with the patients in mind who had pathological regulation of body temperature. However, all the animal experiments were conducted on normal animals. And various stressful conditions activated stress induced hyperthermia (SIH), in man in the absence of disease. It was noted that emotional stress, such as examination stress, increased $\mathrm{Tc}$ in healthy human subjects. However, in most cases, its magnitude was $<1^{\circ} \mathrm{C}$ and the maximal Tc they show was $<37.5^{\circ} \mathrm{C}$.

After repeated stress the animals learnt to anticipate the stress and responded with SIH. This is a classical conditioned response. Normal human individuals also showed temperature elevation after stress [14].

But why is this necessary? What is the biological significance of SIH? Does it contribute to host defense against various nocuous agents as the stress response may be considered to be an emergency defense reaction [9], the "general adaptation syndrome" as defined by Hans Selye [15]. The stress reaction activates the innate immune system, which may lead to APR, where fever is generated by immune derived mediators [9].

But here we are dealing with a psychogenic pathway of elevating temperature. Nevertheless SIH is definitely part of the stress response and therefore, it should have survival value under dangerous situations. Does this psychogenic elevation of temperature boost the energy reserve and facilitate escape in response to danger? Does it boost independently immune defense? What about helping healing and recovery via immune and metabolic activation? etc. Future experiments are required to answer the questions with regards to the significance of fever.

\section{REFERENCES}

[1] Nowotny A. In search of active sites in endotoxins. In: Nowotny A, editor Beneficial Effects of Endotoxins. New York: Plenum Press, 1983. p. 1.

[2] Boivin A, Mesrobeanu J, Mesrobeanu L. Technique pour la preparation des polysaccharides microbiens specifiques. CR Soc Biol. 1933; 113: 490.

[3] Bertok L, Berczi I. Nomenclature and significance of innate/natural immunity and species specific resistance. Advances in Neroimmune biology. 2011; 1: 11.

[4] Bertók L. Radiodetoxified endotoxin as a potent stimulator of nonspecific resistance. Persp Biol Med. 1980; 24: 61.

[5] Berczi I, Bertok L, Bereznay T. Comparative studies on the toxicity of Escherichia coli lipopolysaccharide endotoxin in various animal species. Can J Microbiol. 1966; 12: 1070

[6] Ramachandra RN, Sehon AH, Berczi I. Neuro-hormonal host defence in endotoxin shock. Brain Behav Immun. 1992; 6: 157.

[7] van der Meer MJ, Sweep CG, Pesman GJ, Tilders FJ. Hermus AR Chronic stimulation of the hypothalamuspituitary-adrenal axis in rats by interleukin 1beta: Central and peripheral mechanisms. Cytokine. 1996; 8(12): 910.

[8] Berczi I, Bertok L, Chow DA. Natural immunity and neuroimmune host defence. Ann NY Acad Sci. 2001; 917: 248.

[9] Berczi I, Szentivanyi A. The acute phase response. In Neuroimmmune Biology, Volume 3: The ImmuneNeuroendocrine Circuitry. History and Progress. Berczi I, Szentivanyi A, Editors, Elsevier, Amsterdam, 2003. p. 463.

[10] Moltz H. Fever: Causes and consequences. Neurosci Biobehav Rev. 1993; 17(3): 237.

[11] Yan X, Xiu F, An H, Wang X, Wang J, Cao X. Fever range temperature promotes TLR4 expression and signaling in dendritic cells. Life Sci. 2007; 80: 307.

[12] Zhao W, An H, Zhou J, Xu H, Yu Y, Cao X. Hyperthermia differentially regulates TLR4 and TLR2-mediated innate immune response. Immunol Lett. 2007; 108: 137.

[13] Berczi I, Quintanar Stphano A, Kovacs K. The brave new world of Neuroimmune Biology. In New Insights to Neurimmune Biology, Berczi I, editor. Elsevier, Amsterdam 2010. p. 4. Elsevier Insights, www.amazon.com.

[14] Oka T, Oka K. Mechanisms of psychogenic fever. (In this issue).

[15] Selye H. The general adaptation syndrome and the diseases of adaptation. J Clin Endocrinol. 1946; 6: 117. 